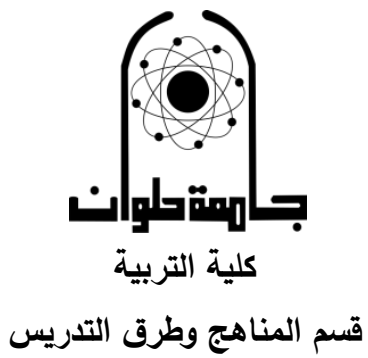

برنامج مقتزع قلئمعلى الأنشطة الموسيقية لذفض المشكلات السلوكية

$$
\text { وتنمية المهارات المياتيةلألأطفال }
$$

The Effectiveness Of Program Based On The Musical Activities To Overcome The Behavior Problems And

Developing The Life SkillsTo The Children

$$
\text { هبه وجمقدمئيمن البلحثة }
$$

همعلمة التربيية الموسيقيتبالقسمين الدوليين الأمهريكي

$$
\text { والبريبطلنيبمدارسبيورسعيددللغاتبالزيهالك }
$$

بلحثةبـهرولة المطاجستيربقسم المناهج و طرق التدريدس

$$
\text { كلية التربية - جلمعتحطوان }
$$

أ. د / مانيرفا رشدي أمين

أستاذ المناهج و طرق

التدريسووكيلكالية

التربيةلالدراسات العليا

والبحوث السلبقكلية التربية

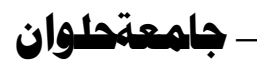

أ. د / آمال أهمدمفتاروادق

أستاذعلم النفس التربيوي

$$
\text { ونلئب }
$$

رئيسجامعتحلوانسلبقالشئونذديمة

المجتمع وتنسمية البيئة 


\section{مستخلص البهث}

هدف البحث إلى التحقق من فاعليتبرنامجقائمعلى الأنشطة الموسيقيةلخف

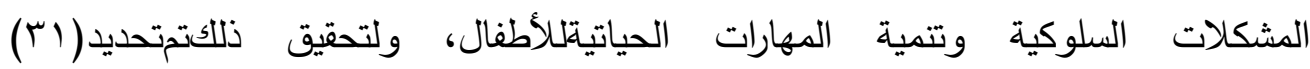

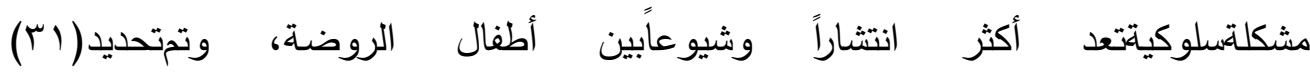

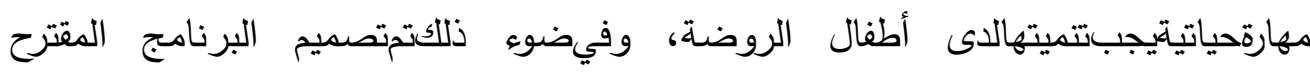

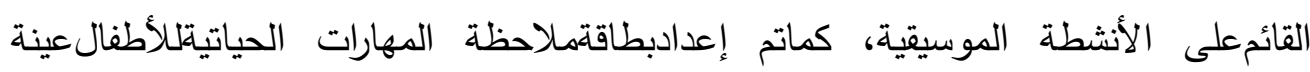

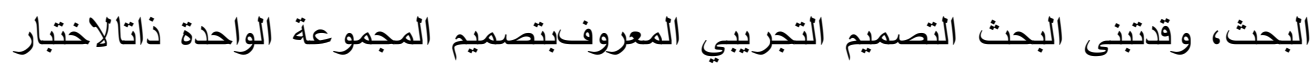

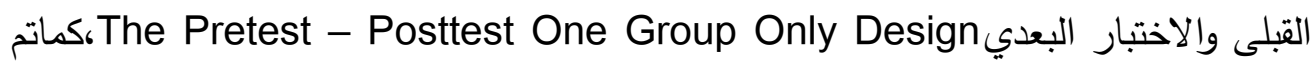

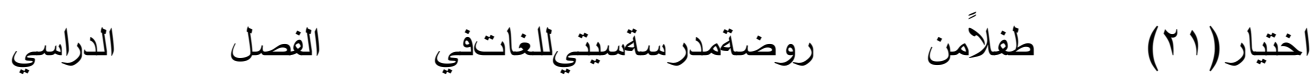

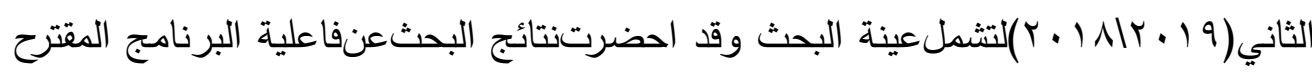

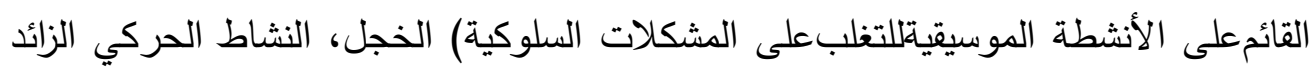

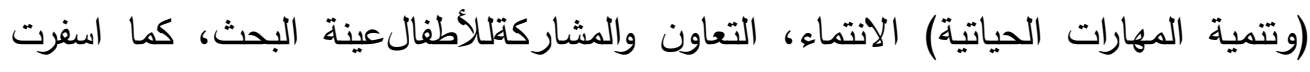

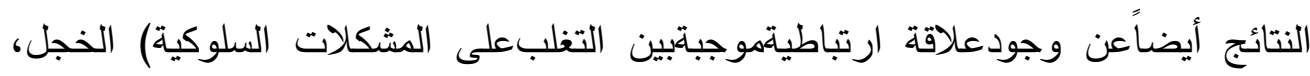

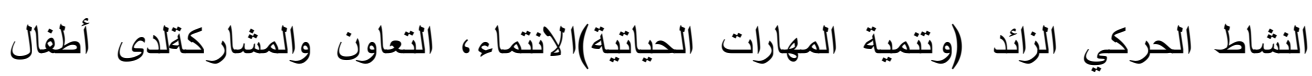

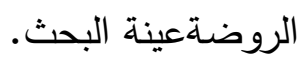




\section{Summary of the research}

The aim of this study is to identify the effectiveness of a program based on musical activities to overcome behavioral problems and develop the life skills of children. In order to achieve this, 31 behavioral problems were identified which are more common among Kindergarten children. 31 life skills In the light of which the proposed program based on musical activities was designed. The life skills note for the children of the sample was also prepared. This research was adopted by the experimental design known as the pre-test and post-test group The Pretest - Posttest One Group Only Design, as a Stream (21) children from kindergarten City Language School in the second semester $(2018 \backslash 2019)$ to include the research sample.

The results of the research on the effectiveness of the proposed program based on musical activities to overcome behavioral problems (shyness, hyperactivity) and life skills development (belonging, cooperation and participation of children of the sample of the research). The results also revealed a positive correlation between overcoming Behavioral problems (shyness, excessive motor activity), and life skills development (belonging, cooperation and participation) among kindergarten children. 


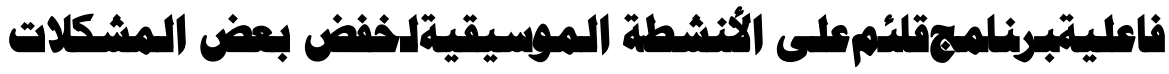 \\ السلوكية وتنمية المهارات الميلتية للأطفال
}

\author{
إعســـــاد \\ هبة رجائي على دياب
}

المقدمة

تلعب الموسيقىدورا وظيفيا أكبربكثيرمنمجرد المتعة والترفيه، كماتعددت الأدوار

التيقامتبها الموسيقى والأنشطة الموسيقية، فمنها الدور الوجداني القومي والدور التهذيبي

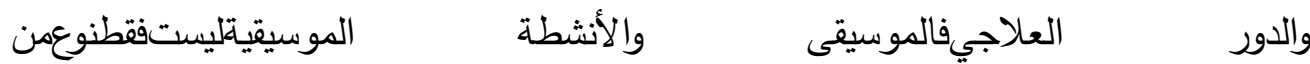
الترفيهيمكنممارستاتخفيفامنعناء العمل والتفكير ، إنماهي دراسةجادةلهاقيمة وفائدةفي ذاتها،

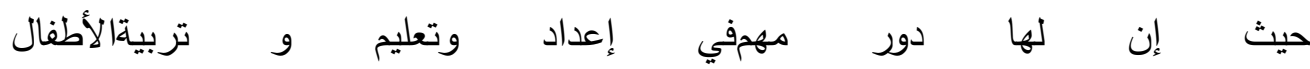
وتحقيقنموأثشاملاًتكاملافِيمختلفنواحيشخية الطفل الجسمية والعقلية والمعرفية والانفعالية

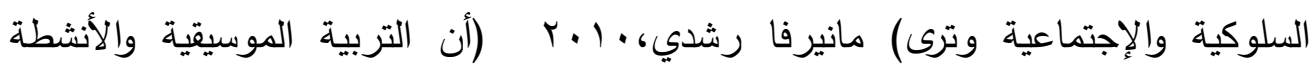

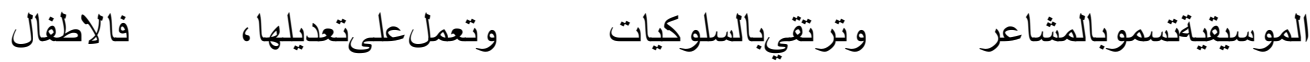

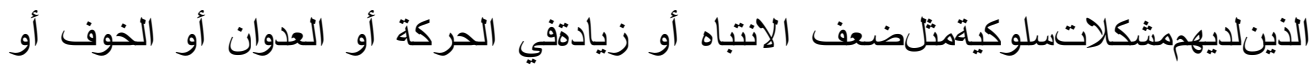

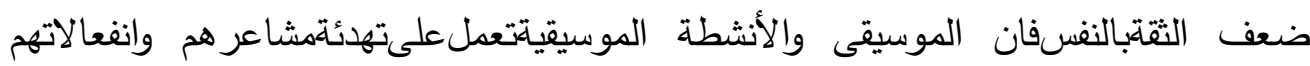
إضافة إلى أنهاتساعدعلى زيادة القدرعلى الابتكار والتخيل والابداع وتتميةمهارات الحياهلديهم.

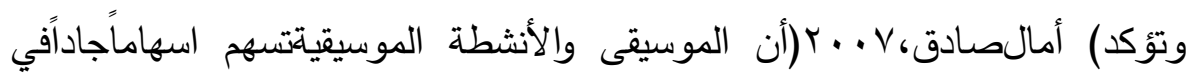
التحكم في الانفعالات والسلوكيات المختلفةخصوصاًغير السارةمنهاعن طريق الاستماع واستثارة انفعالات وسلوكياتمقبولةكالسرور والاحساسبالبهجة والمشاركة الوجدانية،

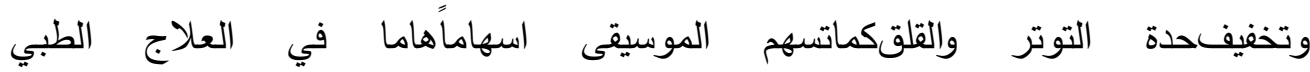

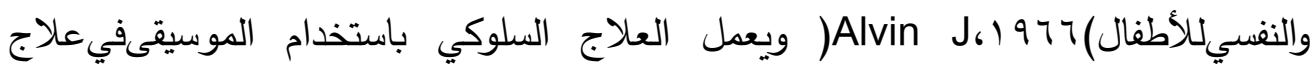

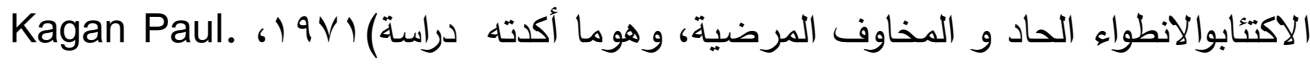
London 
التوتر العضلي وتتمية التآزر الحركي وتهيئة الفرصلاختزال التوتر الانفعالي السلوكي والتعبير الابتكارىعن الذات.

وتعدعمليتتمية المهارات الحياتيةمننواتج التعلم المهمةلكثيرمن المناهجفي أي مرحلة دراسية وفي رياض الأطفالبصفةخاصةفهذا الأمر لايقتصر علىمادةبعينها دون المواد

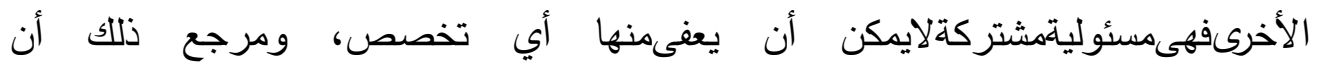

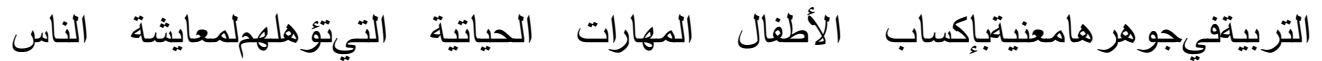
والتعاملمعهم وتمكنهم من العمل والمشاركتفي العملية التموية.

فالمهارات الحياتيةعلىهذا النحوترتبط ارتباطا وثيقابعلم الموسيقى، حيث إنهاتهدف إلىتحسينالحياة النفسية والاجتماعيةللأطفال وتتمية المهارات الشخصية والاجتماعية والسلوكية، مثل الاتصال والتعاونمع الاخرين وممارسة العملضمن الفريق الواحد وتزويدهمبالمعلومات والخبرات المتعلقبإبارة المواقف الحياتية اليومية واطلاعهمعلى التقنيات الحديثة وتوجيههملاستخدام الأمثللها.

وانطلاقاًمماسبق ومنمكانةعلم الموسيقى ومدى أهميتها وارتباطهابالطفل

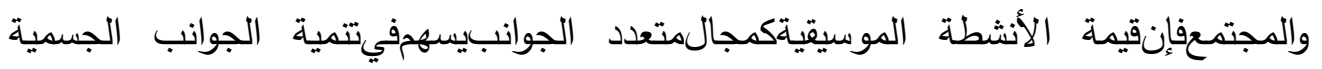
والعقلية المعرفية والانفعالية السلوكية والمهارية والاجتماعيةمنشخصية الطفل وبالطبعفإنهذه الطئه

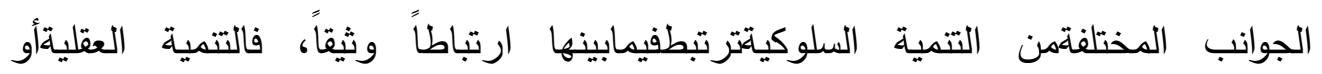

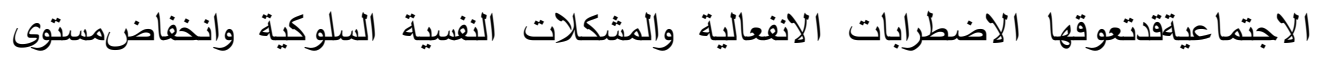
المهارات الحياتيتلدى الأطفال، لذلكترى الباحثة أن استخدام الأنثطة الموسيقية) الغناء -

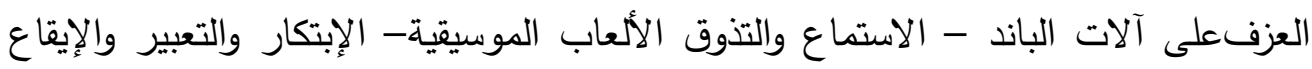
الحركي (ضمن أنشطة الروضة اليوميةكمايجب و بطريقةفاعلة، سوفتعملعلىتفريغ

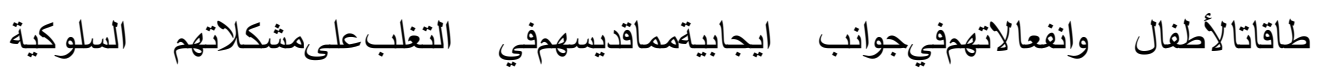

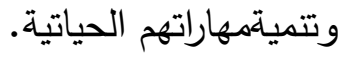

\section{Problem Of The Research}

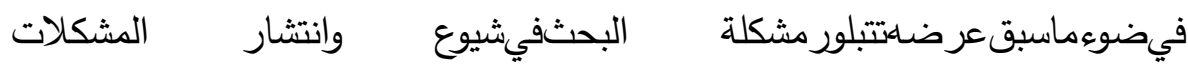
السلوكيةمثل)(الخجل النشاط الحركي الزائد (وانخفاضمستوى المهارات الحياتيةمثل) الإنتماء، 
التعاون والمشاركة (لدى أطفال الروضةمما دفع الباحثةلقيامبالبحثلتقصيفاعلية البرنامج

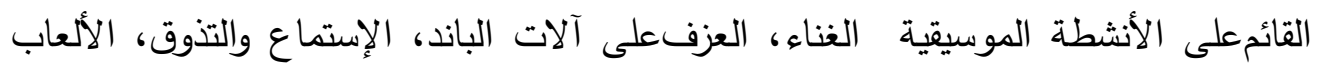

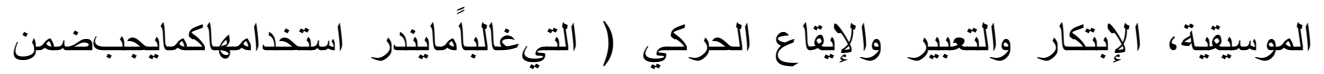
أنشطة الروضة اليومية ) علىحدعلم الباحثة (والتيقديمكنمنخلالها التغلبعلى المشكلات السلوكية وتتمية المهارات الحياتيتلأطفال.

\section{أسئلة البمث: Questions of The Research}

حاول البحث الإجابةعن السؤال الرئيسي التالي:

مافاعلية البرنامج المقترح القائمعلى الأنثطة الموسيقيةلتغلبعلى المشكلات

السلوكية وتتمية المهارات الحياتيتلأطفال؟ ماعله

وتفرعمنهذا السؤال الرئيسي الأسئلة الفرعية التالية:

1- ماالمشكلات السلوكية الأكثرشيوعاً وانتشاراًبين أطفال الروضة؟

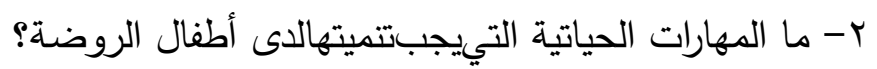

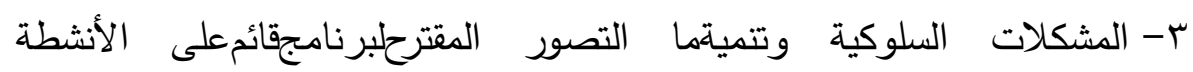

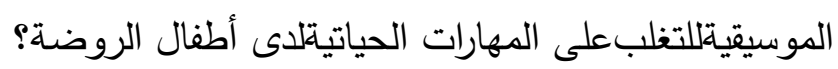

ع- مافاعلية البرنامج المقترح القائمعلى الأنشطة الموسيقيةلتنغلبعلى المعلى المشكلات

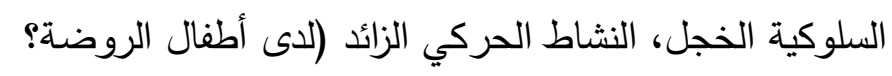

ه- مافاعلية البرنامج المقترح القائمعلى الأنثطة الموسيقيةلتتمية المهارات الحياتية)

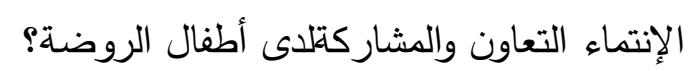

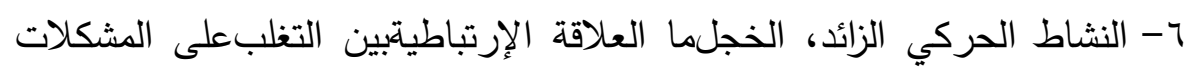

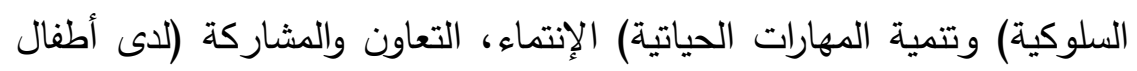

الروضة

\section{Aims of The Research}

هدف البحث إلى:

1- تحديد المشكلات السلوكية الأكثرشيوعاً وانتشارابين أطفال الروضة.

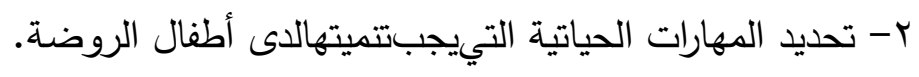


r- تصميمبرنامجقائمعلى الأنشطة الموسيقيةلأطفال الروضة.

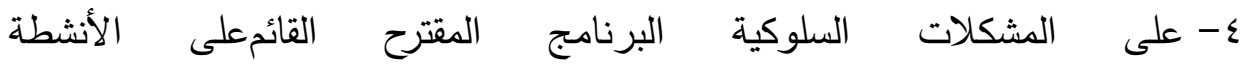
الموسيقيتللتغلبقياسفاعلية الخجل، النشاط الحركي الزائد (لاى أطفال الروضة. 0- الإنتماءقياسفاعلية البرنامج المقترح القائمعلى الأنثطة الموسيقيةلتنمية المهارات الحياتية التعاون والمشاركةلدى أطفال الروضة.

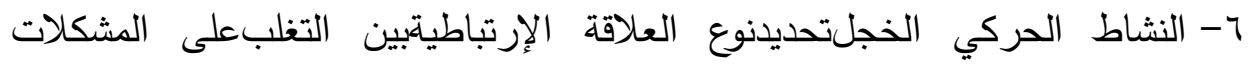
السلوكية الزائد (وتتمية المهارات الحياتية) الإنتماء، التعاون والمشاركة (لدى أطفال الروضـة.

\section{فروض البمث: Hypotheses of The Research}

حاول البحث التحققمنصحة الفروض التالية:

1- البحثفيبينمتوسطي درجات أطفالعينة (0. يوجدفرق دال إحصائياً عندمستوى) التطبيق القبلي والبعديلبطاقةملاحظةمشكلتي الخجل، والنشاط الحركي الزائدلصالح التطبيق البعدي.

r- البحثفيبنمتوسطي درجات أطفالعينة،ه.يوجدفرق دال إحصائياً عندمستوى) التطبيقين القبلي والبعديلإختبار الثفهيلمشكلتي الخجل، والنشاط الحركي الزائدلصالح التطبيق البعدي. r- بينمتوسطي درجات أطفالعينة البحثفي، ه.يوجدفرق دال إحصائياًعندمستوى) التطبيقين القبلي والبعديلبطاقةملاحظةمهارتي الإنتماء، والتعاون والمشاركةلصالح التطبيق البعدي.

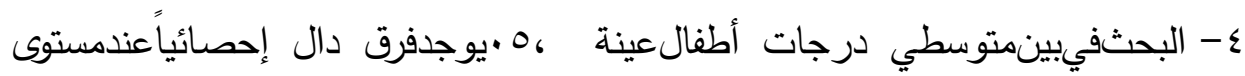
التطبيقين القبلي والبعديللإختبار الثفهيلمهارتي الإنتماء، والتعاون والمشاركةلصالح التطبيق البعدي. 0- الخجل، والنشاط الحركي الزائد، وتتميتتوجدعلاقة ارتباطيةموجبتبين

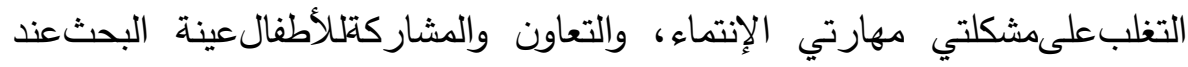
اعتبار درجاتهمفيطاقة الملاحظة. 
1- الخجل، والنشاط الحركي الزائد، وتتميتتوجدعلاقة ارتباطيةموجبتبين

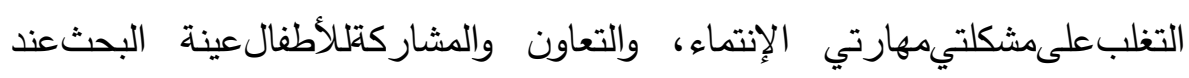
اعتبار درجاتهحفي الإختبار الثفهي.

\section{أهمية البمث: Significance of The Research}

\section{البحثكلمنققتفيدنتائج:}

1 - الأطفالفي التغلبعلى المشكلات السلوكية وتتمية المهارات الحياتيةلديهم. r- الأطفالفي التغلبعلى المشكلات السلوكية وتتمية المهارات الحياتيتلديهم المشكلات السلوكية وتتمية المهارات الحياتيتلاى أطفال الروضة. r- البحثللتغلبعلى المشكلاتفيمعلمي التربية الموسيقيةفيكيفيتتوظيف البرنامج

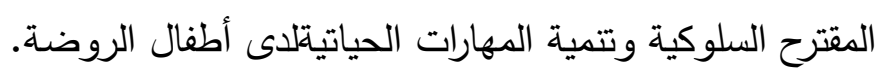

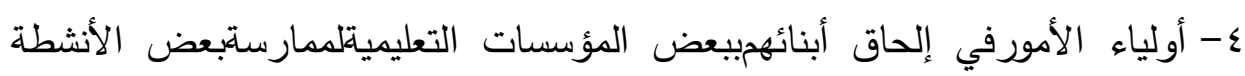

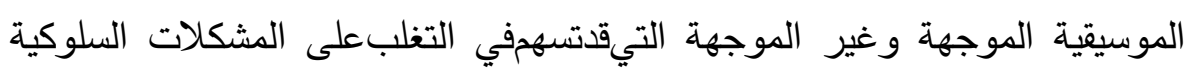
وتتمية المهارات الحياتيةلدى أطفال الروضة.

\section{مدود البسش: Delimitation of The Research}

1- اقتصر البحثعلى التغلبعلى المشكلات السلوكية) الخجل، النشاط الحركي

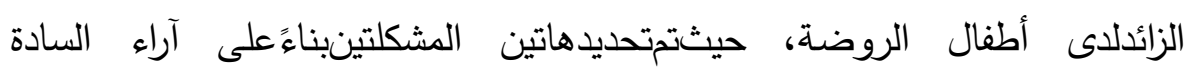

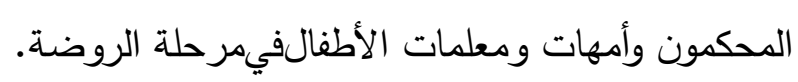
r- اقتصر البحثعلىتتمية المهارات الحياتية) الإنتماء، التعاون والمشاركة (لدى أطفال

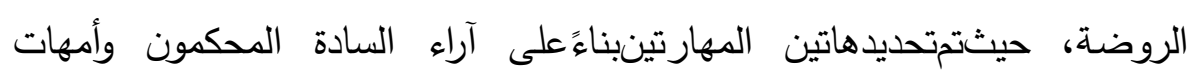
ومعلمات الأطفالفيمرحلة الروضة. r- الأنشطة الموسيقية الخمسة، وهي) الغناءفي البحث استخدمفيتصميم البرنامج المقترح العزفعلى آلات الباند - الاستماع والتذوق - الألعاب الموسيقية - الإبتكار

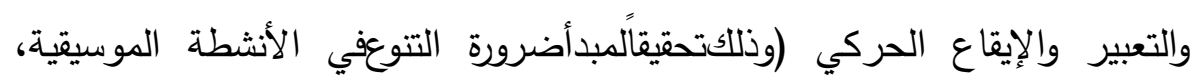
والذيقديسهمفي التغلبعلى المشكلات السلوكية وتتمية المهارات الحياتيتلدى أطفال الروضة. 
ع - اقتصرتجريب البحثعلىعينةمن أطفال)Kg2( من روضةمدرستسيتيللغات

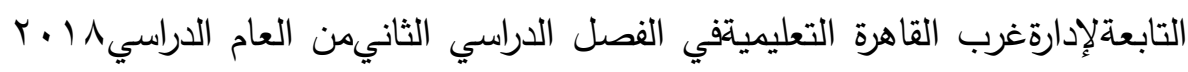
/ / ب ب وذللك لاعتبارات عمليةخاصتبإِإكانيتتطبيقتجربة البحث.

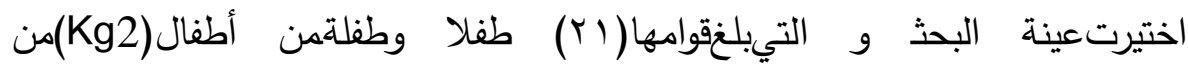
روضةمدرسةسيتي للغات التابعةلإدارةغرب القاهرة التعليميةبالطريقة المقصودة، وفيهذها

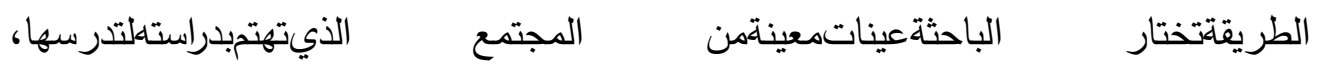
وذلك لاعتبارات عمليةخاصتبإمكانيةتطبيقتجربة البحث.

\section{أدوات البمث: Tools of The Research}

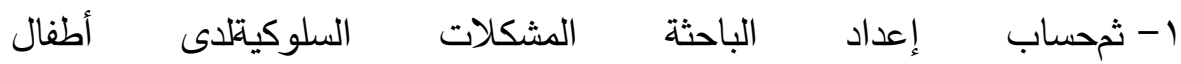

$$
\text { الروضةبطاقةملاحظةلقياس صدقها وثباتها. }
$$

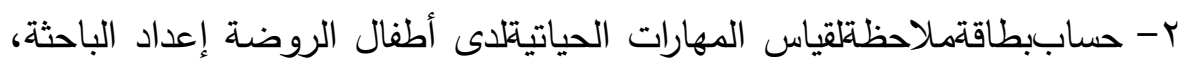

$$
\text { ثمصدقها وثباتها. }
$$

r- حساب، ثم (الروضة) إعداد الباحثقلقياس المشكلات السلوكيةلدى أطفال

$$
\text { إختبارشفهي صدقه وثباته. }
$$

ع - إختبارشفهيلقياس المهارات الحياتيةلدى أطفال الروضة إعداد الباحثةثمحساب

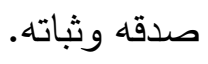

\section{منهج البمث وإجراء|ته: Method of The Research :}

$$
\text { تبنى البحثمنهجينمنمناهج البحث العلمي، هما: }
$$

المنهج الوصفي: والمنهج التجريبي وتمت إجراءات البحث وفقاًلخطوات الآتية:

\section{أولا: الإطار النظري:}

$$
\text { وتضمن دراستةمايلي: }
$$

1- الأنشطة الموسيقيةمنحيثتعريفها وأهميتها، وأهدافها، وأنواعها. 
r- والنشاط المشكلات السلوكيةمنحيثتعريفها، وتصنيفاتهامع التركيزعلىمشكلتي الخجل الحركي الزائد.

ب- التركيز علىمهارتي الإنتماء، والتعاون المهارات الحياتيتمنحيثتعريفها، وتصنيفاتهامع والمشاركة.

\section{ثليا: الدراسة البميدلنية}

تضمنت إجراءاتتصميم البرنامج القائمعلى الأنشطة الموسيقيةمايلي: 1- إعدادقائمةبالمشكلات السلوكية الأكثرشيوعاً وانتشاراًبين أطفال الروضتثث اختيارمشكلتي الخجل، والنشاط الحركي الزائدبناءًالى آراء السادةالمحكمون وأمهات ومعلمات أطفال الروضةتلتغلبعليهامنخلال البرنامج المقترح في البحث.

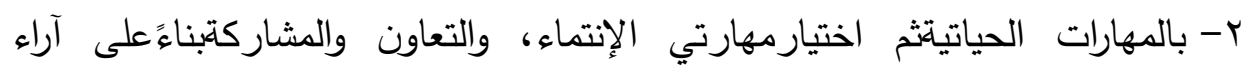
إعدادقائمة السادة المحكمون وأمهات ومعلمات أطفال الروضةلتتميتهالدى أطفال الروضةمنخلال البرنامج المقترحفي البحث.

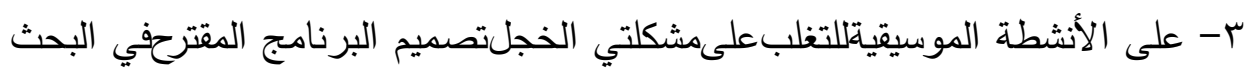
القائم والنشاط الحركي الزائد، وتتميةمهارتي الإنتماء، والتعاون والمشاركةلدى أطفال

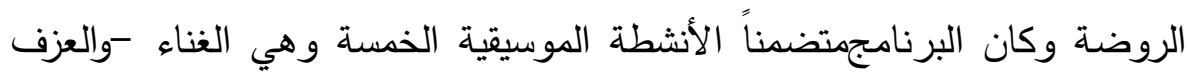

$$
\text { على آلات الباند. }
$$

ع - فيصورته النهائيةتعديله، ووضعهعلىمجموعةمن المحكمين، ثمعرض البرنامج.

$$
\text { 0- إعداد أدوات البحث وتمثلتفي: }
$$

أ-بطاقتملاحظةلقياس المشكلات السلوكيةلدى أطفال الروضة إعداد الباحثة وحساب صدقها وثباتها. ب-بطاقةملاحظةلقياس المهارات الحياتيتلدى أطفال الروضة إعداد الباحثة، وحسابصدقها وثباتها. ج-إختبارشفهيلقياس المشكلات السلوكيةلدى أطفال الروضة إعداد الباحثة وحساب صدقه وثباته. 
د-إختبارشفهيلقياس المهارات الحياتيةلدى أطفال الروضة إعداد الباحثة وحسابصدقه

وثباته.

\section{ثالثا: تمبرة البمث}

وتضمنت:

1- إختيارعينة البحثمن أطفالKg2من روضة مدرستسيتيللغات التابعةلإدارةغرب

القاهرة التعليمة.

r- السلوكية ـ بطاقةملاحظة المهارات الحياتية ـ الإختباربطاقتملاحظة المشكلات)

تطبيق أدوات البحث الشفهيللمشكلات السلوكية ـ الإختبار الشفهيللمهارات الحياتية

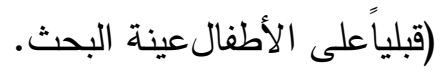

r- تدريس البرنامج المقترحفي البحثللأطفال عينة البحث.

ع - تطبيق أدوات البحثبعدياً على الأطفال عينة البحث.

رابعاً: المعالجة الإحصائيةتللبيانات والتوصل إلى النتائج

خامساً: تفسيرنتائج البحث ومناقشتها، وتقديم التوصيات والمقترحاتفيضوءنتائج البحث.

\section{Definition of The Research :}

1- الأنشطة الموسيقية

وقدتوصلت الباحثة إلىتعريف الأنشطة الموسيقية إجرائياًي البحثعلى أنها"

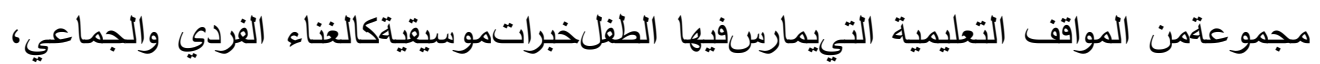
والعزف الفردي والجماعي على آلات الباند، والإستماع والتذوق، والألعاب الموسيقية، والإبتكار

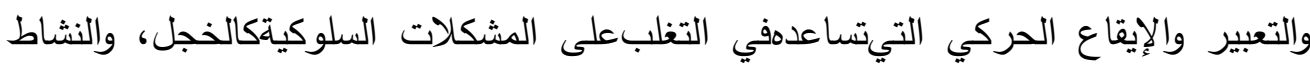
الحركي الزائد وتتميلديه المهارات الحياتيةكالإنتماء، والتعاون والمشاركة.

\section{r-المشكلات السلوكية}

فيضوهماتقدفقدصاغت الباحثة التعريف الإجرائيللمشكلات السلوكيةفي البحث، بأنهالأفعال والاستجابات التيتظهر على طفل الروضة أو تصدر عنهبصفتمتكررة 
أثناءتفاعلهمع زملائه الأطفال ومعلماتهفي الروضة، ولاتتقممعمعايير السلوك السوي المتعارفعليمللأطفـالفيهذه المرحلة متلمشكلة الخجل والميل إلى النشاط الحركي الزائد. أ-الخجل

وتعرف الباحثة الخجل إجرائياًأنه "شعور طفل الروضةبالقلق والتردد وضعف

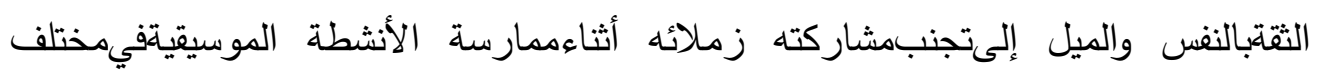
المواقف التعليمية. ب-النشاط الحركي الزائد وتعرف الباحثة النشاط الحركي الزائد إجرائياًأنها نشاطجسميحركيقومبه طفل

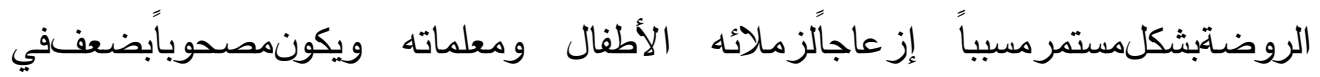
التركيز وتشتت الانتباه وتوتر وقلق والثعوربالدونية والعزلةعن زملائه الأطفال".

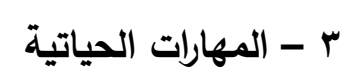

عرفت الباحثة المهارات الحياتية إجرائياً البحثبأنهاعبارةعن "السلوكيات التيتمكن

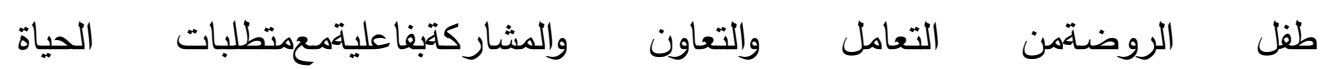

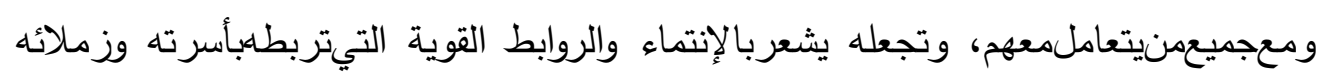
ووطنه وتوحدمدعهم. أ-الإنتماء

وتعـرف الباحثة الإنتماء إجرائيافي البحثبأنه" ارتباط طفل الروضتةبزملائه

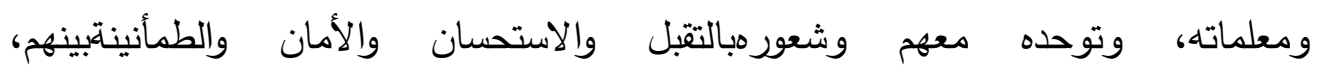

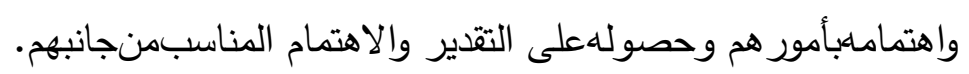
ب-التعاون والمشاركة وتعرف الباحثة التعاون والمشاركة إجرائياًي البحثبأنه " تعاون طفل الروضة ومشاركتهلزملائه أثناءممارسة الأنشطة الموسيقية المختلفة، التيقدتبعدعنه الثعوربالخجل وترشدلديه النشاط الحركي الزائد وتتميلديه الإنتماء والتعاون والمشاركة. 
إن قيمة و أهمية الأنثطة الموسيقيةكجالمتعدد الجوانبيسهفيكلمن التتمية

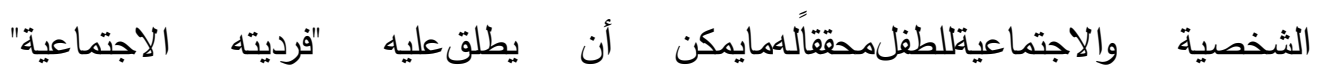
والتيتتضمنتحقيق الذات، والكفاءة الاجتماعية، وتزخر الأدبيات التربوية المعنية ) مانيرفا

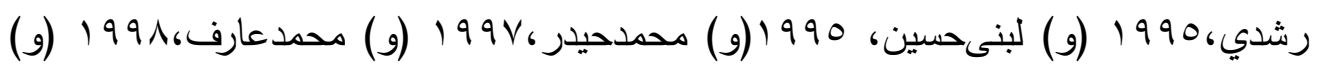

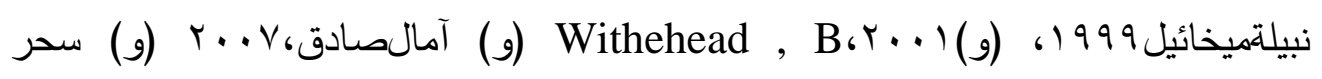

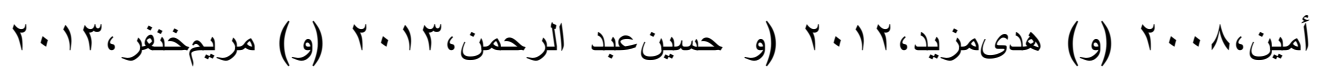

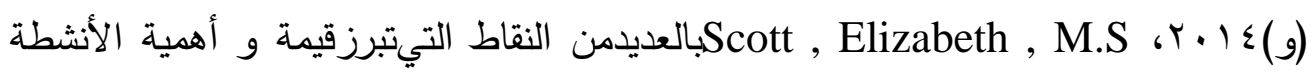
الموسيقيةفيتحقيق النمو الثامللثخصية الطفل، والتيمن أهمهامايلي: 1- تتميلدى الطفل الاحساسبالمبادأة و المسئولية و تكسبهبعض أنماط السلوك المرتبطةبالعلاقات الانسانية، كالتعاون و الثقتبالنفس. r- تساعدعلىتطوير الادراك الحسيللطفل وتتشيط العقل، وتسهجفيعلاج الخجل والإنطواءبسببقدرتهاعلى إعطاء الطفل الفرصةتلتعبير عن الذات.

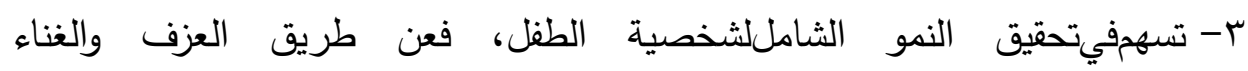

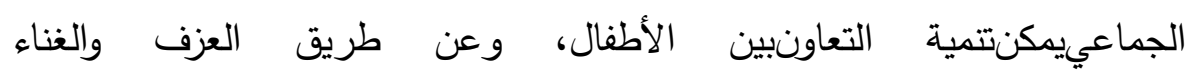
الفرديمكنتتمية الثقتبالنفس والاستقلاليةلدى الطفل. ع- تسهحفيتخفيفحدة التوتز والقلقلدى الأطفال وتزيدمن دافعيتهم وإقبالهمعلى العمل المدرسي.

ه- تلعب دوراً كبيراًفي التحكمفي الانفعالات المختلفةخصوصاً الغير السارةمنها.

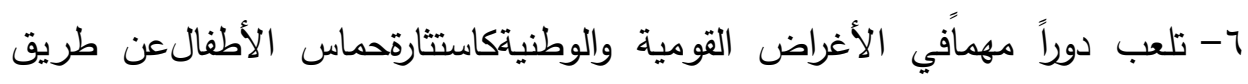
المشاركتفي الأنثطة الموسيقية المختلفة في المناسبات الوطنية المختلفة. V- تسهحفيتبيت القيم الدينية والخلقية وتدعيمها، وذلكعن طريق الغناءفي المناسبات الدينية. 1- تقومبدورترفيهيمهمللطفلمنخلالممارستهلهافي وقت الفراغممايجنبه الانحراف. 
9- تتمي روح الفريق المتنافسبينماعات الأطفال، وذلكفي المسابقات المختلفتفي المستويات التعليمية المختلفة. • - - تساعدعلىتنمية الطفلجسميافمنخلال الغناء والعزفعلى الآلات والابتكار والتعبير الحركي والإيقاع الحركيكتسب الطفل التحكمفي عضلاته الدقيقة والكبيرة.

\section{ثلنيا: المشككلات السلوكيةلدى الأطفال}

تتعدد وتتشعب المشكلات السلوكيةعند الأطفاللدرجةقديصعبمعها أحيانافصل

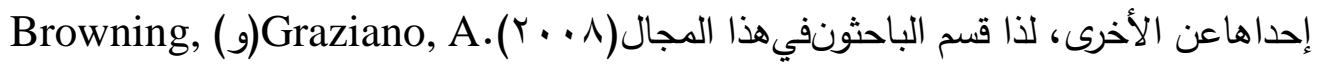

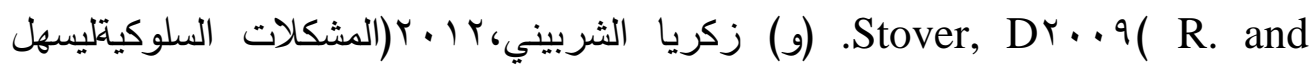
دراستها إلى عدةمكلات رئيسيةيندرجتحتكلمشكلة رئيسية عدةمشكلاتفر عيةكمايلي: 1 - مشكلات إنفعالية: كالخجل، والإنطواء، والغضب، والإكتئاب، والغيرة، والخوف، والأنانية والقلق، وضعف الثقتبالنفس.

r - مشكلات اجتماعية: كالسرقة، والعدوان، والكذب، والعناد، والتخريب، والتمرد. r - مشكلاتحركية: كالنشاط الحركي الزائد، والحركات العصبية، وقضم الأظافر ، ومص

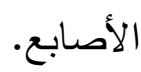
ـ -مشكلات الكلام: كالتهتهه، والتأتأه، والتلعثم، والحبسة الصوتية. ه -مشكلات التغذية: كفقدان الثهية، والثراهة، ورفض الطعام، والقىى، والنحافة المفرطة. 1 - الإخراج: كالتبول اللإرادي.

\section{ثالثا: المهارات المياتية}

أتققمخططو المناهجفي العديدمن الدولعلىتصنيف المهارات الحياتية

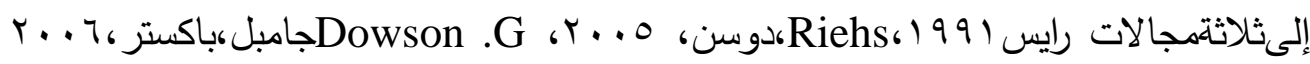
Gamble . Baxter المهني، والمهارات اللازمةللحياةبصفةعامة. وفيمايليشرحلهذه المجالاتبشيءمن التفصيل: 
(1) (1) (المهارات الأساسيقلتعليم

لايقصدبهتعليم القراءة والكتابةفقط، ولكنتعليمهارات أخرىمثل المهارات الحسابية،

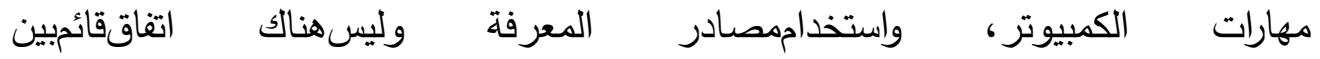
الخبراءعلىكيفيتتنميةهذه المهارات فيمايرتبطبالأسلوب المستخدفيتتميتها المرتبطتبوصول ولهيول المتعلملحد أدنىمحددلها.

ولكنتعلم القراءة والكتابة يعدعنصراً أساسياً تحقيق المهارات الحياتيةلكلفرد داخل المجتمع حيث أن القراءة والكتابة تمثل عناصر و ومقوماتجوهرية، وتعدمهارات أساسيتللتقدمفي عملية التعليم

وتساهمفي استمرار النمو العقليلمتعلملذاتقومعلمات رياض الأطفالبإكساب

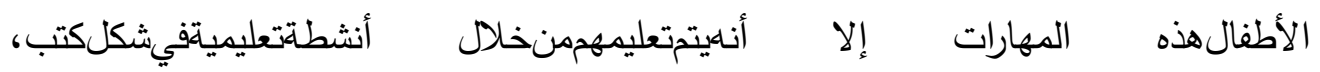
وتزويدهمبواجباتمنزليةلتعليمهم القراءة، والكتابة والحساب.

(r) - (r) - مهارات المجال المهني

هيتلك المهارات العملية المرتبطةبالعمل الحرفي أو المجال المهنيلإعداد

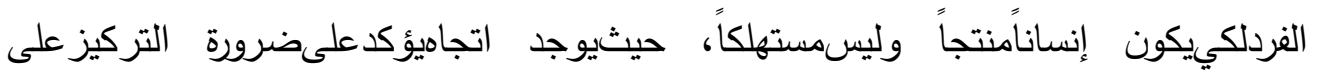

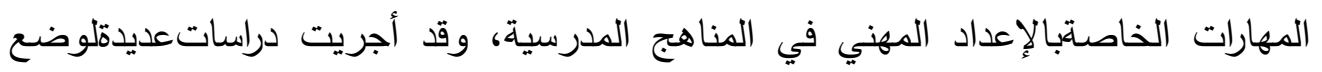

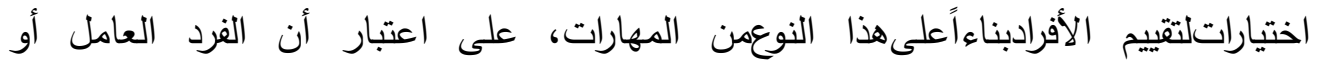

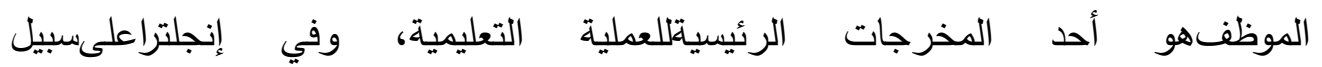

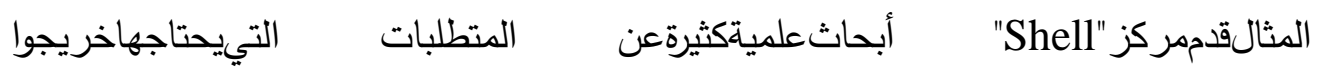
الددارسمنير غبونفي الإلتحاقبالوظائف.

وظهر الاهتمامبهذه المهاراتفيمرحلةماقبل الددرسة، حيث أعدت الأنشطة

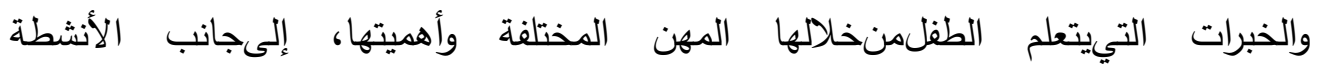
التيتتيحلطفلفر صتممارسة هذه المهن. (r) المهارات اللازمةتلحياةبصفةعامة: 
وهيمهارات التعايشمع المجتمع المعاصر ، حيثيتدرب الفردعلى التكيف، ومواجهة المواقفالجديدة، ومهارات التعاملمع المشكلات، وعلى التمكنمن اتخاذ القرار وأصبحت الآن أدبيات التربية والتعليم، وعلم المناهج، واستراتيجيات التدريسعلىمستوى العالمتركز أكثر علىتنمية مهارات الحياة التيتجعل الفرديتمتعبالقدرةعلى التعايشفيحياته اليومية، ومقابلة ولئل التحديات، وحل المشكلات.

\section{نتلئج البمث، تفنسيرها ومناقشتها}

أولاً: النتائج المتعلقتبالسؤال الأولمن أسئلة البحث، وهو: ما المشكلات السلوكية الأكثرشيوعاً وإنتشاراً بين أطفال الروضة؟

أسفرت إجراءات البحثعنتحديد(ب) مشكلةسلوكيةمنتشرقبين أطفال الروضة، هي

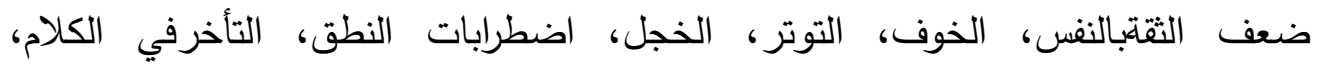

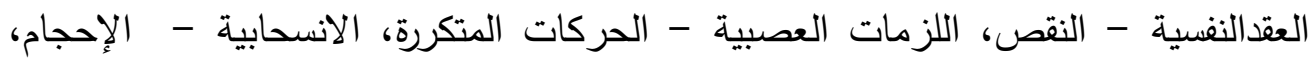
الاعتمادية - عدم تحمل المسؤولية، التتمر أو الإستقواء، العنف، الغضب، العدوان،

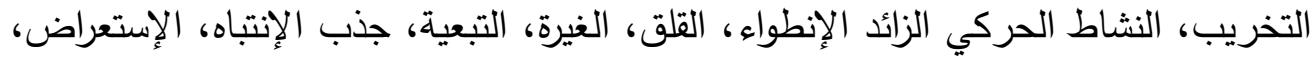

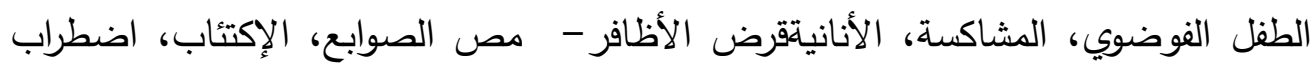
الإنتباه، العناد،التمرد، فرط الحركة - تشتت الإنتباه.

ثانياً: النتائج المتعلقتبالسؤال الثانيمن أسئلة البحث، وهو: ما المهارات الحياتية التيجبتنميتهالدى أطفال الروضة؟ توصل البحث إلىتحديد(اس) مهارة حياتية يجبتتميتهالدى أطفال الروضة، وهذه

$$
\text { المهاراتهي }
$$

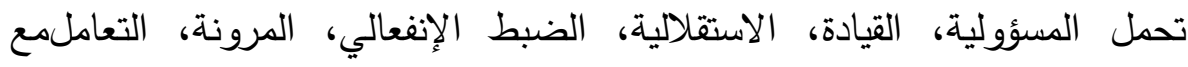

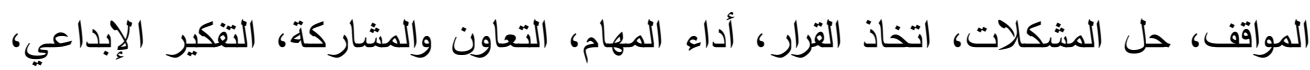
تقديرمشاعر الآخرالتعاطف، التعاملمع المشاعر، التعبيرعن المشاعر، التسامح، التواصل التصل

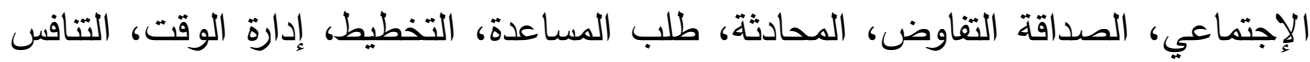
الحر، الإنتماء، المواطنة الإصغاء الجيد، الإقناع، أدب الحوار، النظافة، النظام. 
ثالثاً: النتائج المتعلقتبالسؤال الثالثمن أسئلة البحث، وهو : ما التصور المقترحبرنامجقائمعلى الأنشطة الموسيقيةلتتفلبعلى المشكلات السلوكية

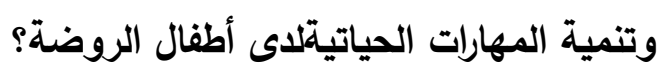

توصلت الباحثة إلىتصميمبرنامجقائمعلى الأثشطة الموسيقيةللتغلبعلى المشكلات

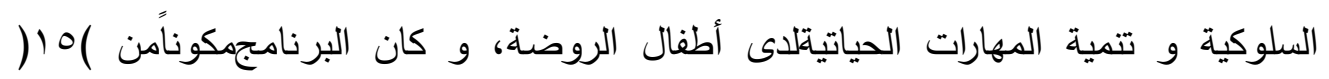
لقاء كتتاولمجمو عقمن الأنثطة الموسيقية المتمثلةفي) الغناء - العزفعلى آلات الباند - الاستماع والتذوق (والتيتمتوظيفهاللتغلبعلىمشكلتي) الخجل النشاط الحركي الزائد (من المشكلات السلوكية، وكذلكتتميةمهارتي) الإنتماء - التعاون والمشاركتمن المهارات الحياتية.

رابعاً: النتائج المتعلقتبالسؤال الرابعمن أسئلة البحث، وهو: مافاعلية البرنامج المقترح القائمعلى الأنثطة الموسيقيتلتغلبعلى المشكلات السلوكية) الخجل النشاط الحركي الزائد (لاى أطفال الروضة الزئج أشارتنتائج البحث إلى أن البرنامج المقترحقد أدى إلى التغلبعلىمشكلتي

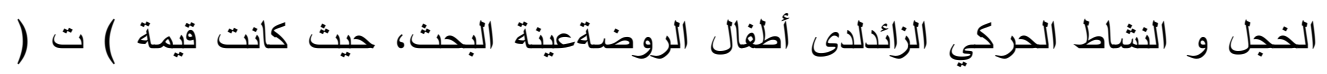

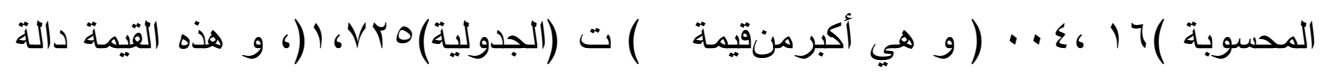

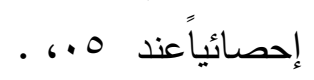

خامساً: النتائج المتعلقتبالسؤال الخامسمن أسئلة البحث، وهو: مافاعلية البرنامج المقترح القائمعلى الأنشطة الموسيقيةتلنمية المهارات الحياتية) الإنتماء،

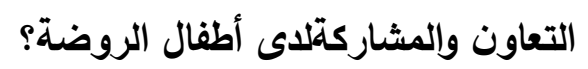

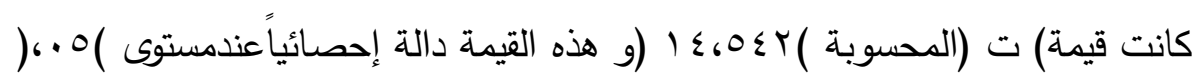

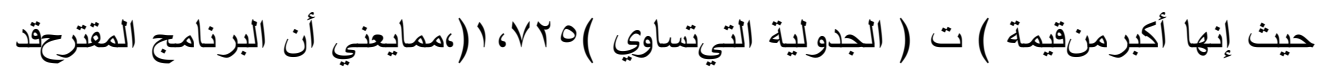

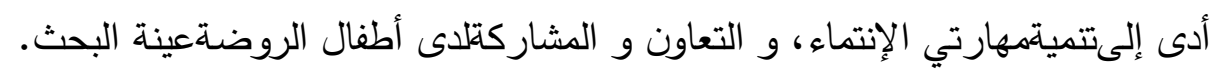


سادساً: النتائج المتعلقةبالسؤال السادسمن أسئلة البحث، وهو: ما العلاقة الإرتباطيةبين التغلبعلى المشكلات السلوكية ) الخجل، النشاط الحركي

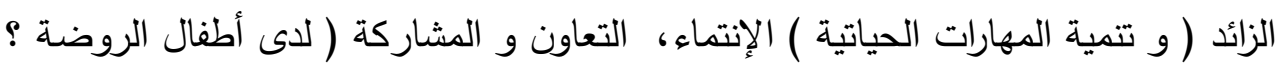
أشارتنتائج البحث إلى وجودعلاقة إرتباطيةموجبةبين التغلبعلى المشكلات السلوكية و تتمية المهارات الحياتيةلدى أطفال الروضةعينة البحث، حيثكانتقيمة الإرتباط

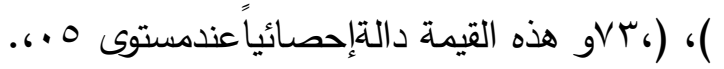

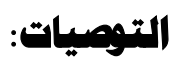

1 بناءمجموعةمن البرامج المترابطة والمتكاملةمعبعضها البعضللتغلبعلى المشكلات السلوكية الأكثر انتشاراًبين أطفال الروضة، ولتهنية ولتمية المهارات

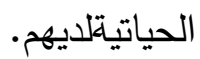
ץ- المهارات الحياتيتلدىعقد دورات تدريبيةلدعلمات الروضة أثناء الخدمةلتدريبهم علىكيفيتتميةأطفال الروضة.

\section{البموث المقترهة:}

1 للتغلبعلىمثكلاتسلوكيةفي البحث إجراء دراستلمعرفة أثر أنثطةموسيقيةغير

$$
\text { التي استخدمت أخرى، وتتميةمهاراتحياتية أخرىلدى أطفال الروضة. }
$$

r- إجراء دراستتستهدفتعرف أثربرنامجتدريبيلمعلمات الروضة أثناء الخدمةفي لئهي

التغلبعلى المشكلات السلوكية وتتمية المهارات الحياتيقلدى أطفال الروضة.

\section{References List قائمة البمسرلجهج}

\section{المراهج العريية:}

1 - أحمدحسين اللقانى على الجمل. r . . r،معجم المصطلحات التربوية المعرفةفى المناهج وطرق التدريس، القاهرة،عالم الكتب. 
r - آلاء رضا رزق ابراهيم. rا ـ r،فاعليةبرنامجلتميتبعض المهارات الحياتيةباستخدام

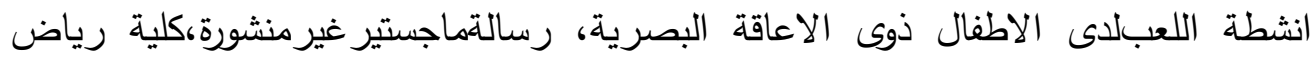
الاطفال،جامعة القاهرة.

r - آمالصادق ، أميمة أمين. 1997، الخبرات الموسيقيةفى دور الحضانة ورياض الأطفال، القاهرة مكتبة الأنجلو المصرية. ع- آمالصادق. 911 1، ،لغة الموسيقى، القاهرة،مركز التتمية البشرية والمعلومات.

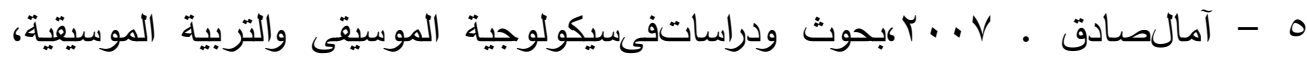
القاهرةكتبة الأنجلو المصرية.

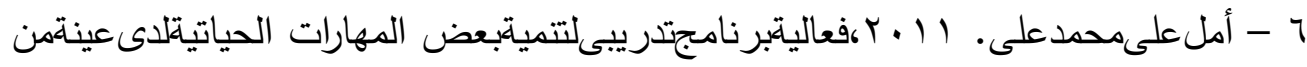
الأطفال التوحديين، رسالةماجستير غيرمنشورة،كلية رياض الأطفال،جامعة الأسكندرية V - ايمان رفعت طه ـ 11 ـ ـ،فاعلية استراتيجية التعلم القائمعلى المشكلتفى اكتساب أطفال

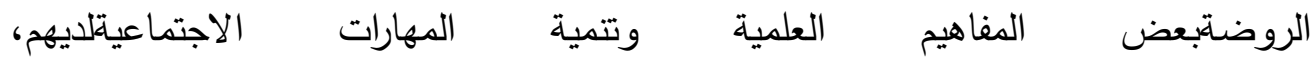
رسالةماجستير غير منشورة،كلية التربيةجامعةحلوان

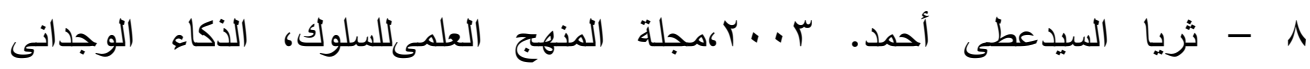
وعلاقتهبالتوافق والتحكم الذاتى،جمعية المرشدين النفسسين، ج r، ع ז،يناير .

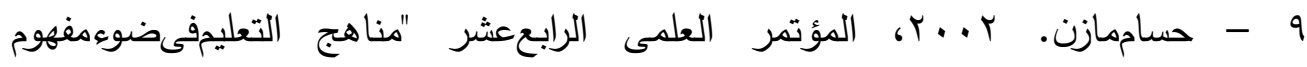
الأداء"،نموذجمقترحلتضمينبعض المهارات الحياتيةفىمنظومة المنهج التعليمىفى إطارمفاهيم

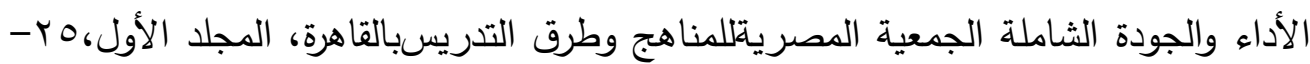
ع بوليو.

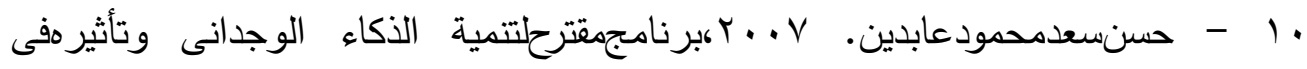
التخفيفمنحدة المشكلات السلوكية المصاحبللصعوبات التعلملدىتلاميذ المرحلة الإبتدائية، رسالة دكتوراهيرمنشورة،كلية التربية،جامعة الأسكندرية.

11 الموسيقيةفي التخفيفمن أعراض الخوف الاجتماعيلدى طالبات المرحلة الإعدادية،مجلة 
التربيةمجلةمكمةللبحوث العلمية و التربوية و النفسية و الاجتماعية،كلية التربيةجامعة

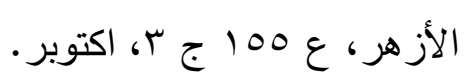
r ا - عمان : دار الفكر .، الموسيقىفىتربية الطفل، • . ب rحنان العناتى. rا - دولوروس أمادى. ؟ . . r، الأنشطة التعليميتلرياض الأطفالهترجمة طارق الأشرف

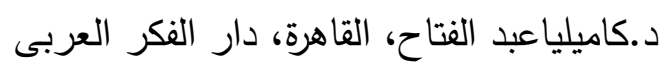

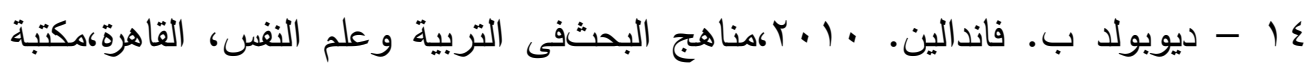
الأنجلو المصرية.

10 - رامىحداد . 1990، دراسة آراء مديري المدارس الثانوية ومعلميهانحو إدخال الموسيقىفى المنهاج المدرسي، رسالةماجستير غيرمنشورة، الجامعة الاردنية.

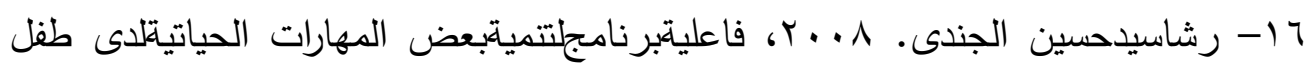

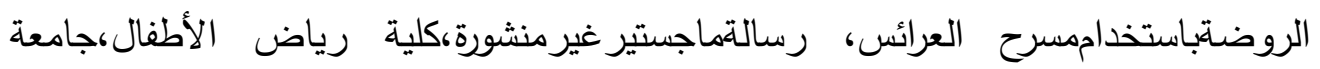
الاسكندرية.

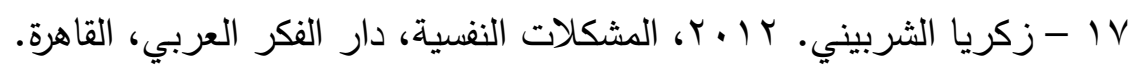
1 ا- سحرسيد أمين. ^ ... r، الموسيقى و ذوي الاحتياجات الخاصة،مؤسسةحورس الدولية، ط ال الإسكندرية. 9 1 - سليمانعبد الواحد ابراهيم. عـ (.ب، المهارات الحياتية : مدخللتعامل الناجحمع الحياة اليومية القاهرةهركز الكتابللنشر • • . F. ومهاراتتطبيقية القاهرة، الدار العربيتللنشر والتوزيع. ا Y - عائشةصبرى، آمالصادق • 99V 1، طرق تعليم الموسيقى، القاهرةمكتبة الأنجلو المصرية.

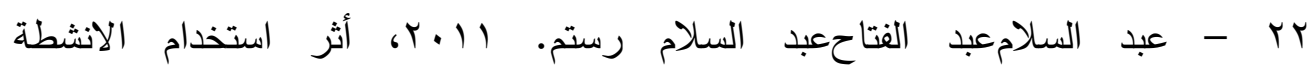

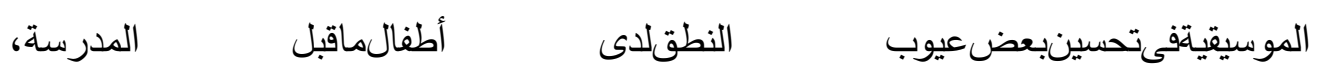
رسالةماجستير غيرمنشورة،معهد الدراسات التربوية،جامعة القاهرة. 
r

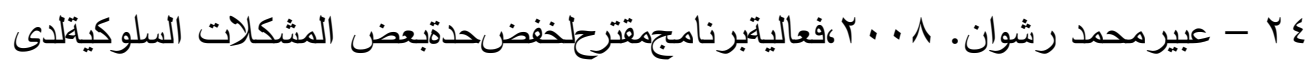

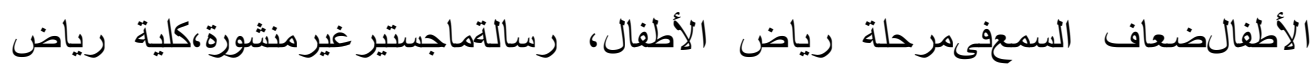
الأطفالجامعة الأسكندرية.

O O - علىماهرخطاب وأخرون. ع . . ب،سيكولوجية النمو، القاهرة، المكتبة الأكاديمية. TY - عواطف ابراهيم. ؟991، الطرق الخاصةتبربية الطفل وتعليمهفى الروضة، القاهرةمكتبة الانجلو المصرية.

الاد - TV الادراك السمعىلدى الأطفال ذوى صعوبات التعليمبالحلقة الأولىمن التعليم الأساسى،معهد الدراسات التربويةجامعة القاهرة

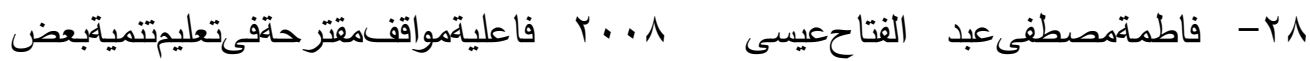
المهارات الحياتيةلطفلماقبل المدرسة، رسالتماجستير غيرمنشورة،كلية التربية،جامعةحلوان. 9r-فرماوىمحمدرماوىحياة المجادى. 9991، مناهج وبرامج وطرق تدريس رياض الأطفال الكويت،مكتبة الفلاح.

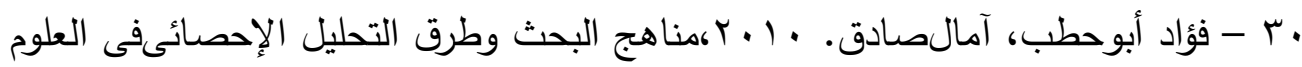
النفسية والتربوية والاجتماعية، القاهرة،مكتبة الأنجلو المصرية.

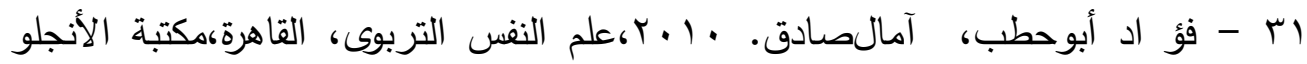

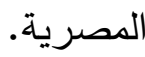
r T - فؤاد أبوحطب، آمالصادق. A . . Y، التقويم النفسى، القاهرة،كتبة الأنجلو المصرية.

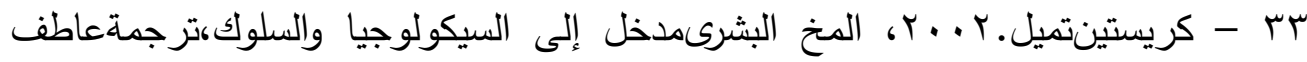

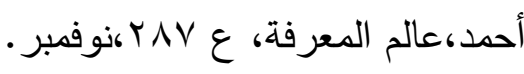

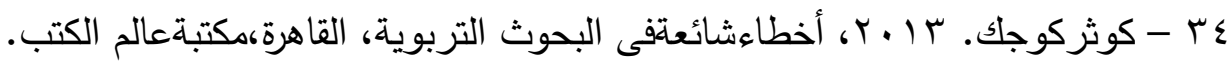


هب -ـلبنىسينعبد اللهعزاز • 1990، أثر استخدامبعض الاستراتيجيات التعليميةعلىتمية الابتكارلدى الأطفالفيمرحلة رياض الأطفال، رسالة دكتوراهيرمنشورة،كلية التربية،جامعةحلوان.

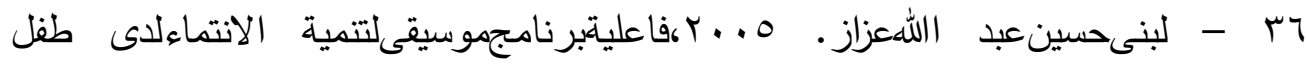
الروضةمجلة دراساتتربوية و اجتماعية،كلية التربية،جامعةحلوانمجلد |(1، عءع، اكتوير •

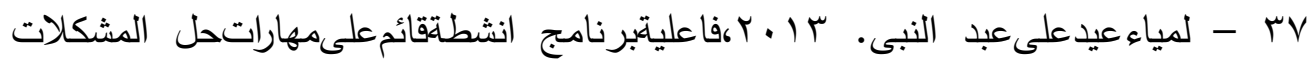

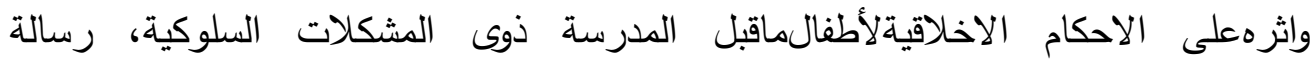
دكتوراهير منشورةمعهد الدراسات التربوية،جامعة القاهرة. ^ץ - مانيرفا رشدى أمين. 990 (،برنامجلتميةبعض المهارات الموسيقيتلطفل الروضة، رسالة دكتوراهغير منشورة،كلية التربية،جامعةحلوان

q T - مانيرفا رشدي أمين. 1 . . Y،فاعليتبرنامجقائمعلى استخدامجموعةمن الأنشطة المتتوعتبالموسيقىبتعليم الطفل المتوحدبعض المهارات الإجتماعية،مجلة دراساتتربوية و وليني

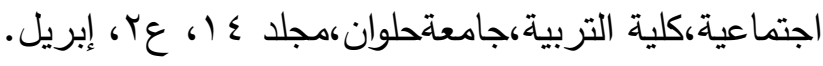
• ـ - مانيرفا رشدى أمين. • ( • r،مخل إلىمهارات التدريس ومعلم التربية الموسيقية، ط r، القاهرة، مكتبة الأنلجو المصرية.

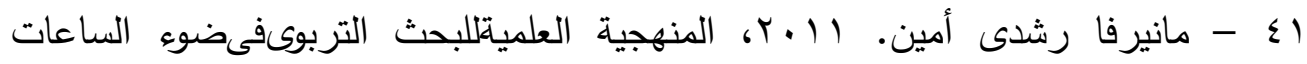
المعتمدةللماجستير / الدكتوراه (، القاهرة، دار مباركللطباعة.

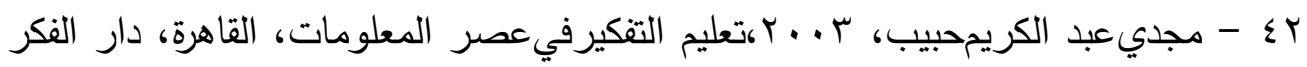
العربى. (- nen

rـ - محمد أبو الفتوحخليل ، خالد الباز ـ 999 1، المؤتمر العلمى الثالث "مناهج العلومللقرن الحادى والعشرين"، دور مناهج العلوجفىتميتبعض المهارات الحياتيتلدىتلاميذ المرحلة

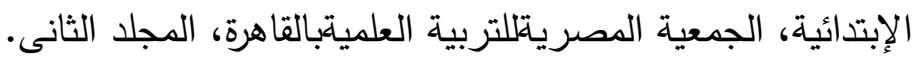




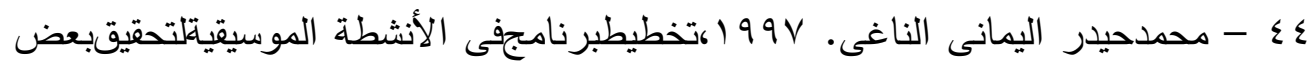

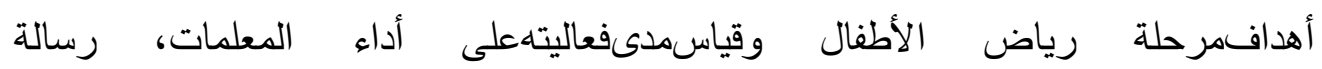
دكتوراهغيرمنشورة،كلية التربيةجامعةحلوان

0؛ - محمدحيدر اليماني الناغي. V.....،فاعلية الأنشطة الموسيقيةفيتمية الذكاء الوجدانيلدى طفل الروضة،مجلة الجمعيةللمناهج و طرق التدريس ع · بهيناير •

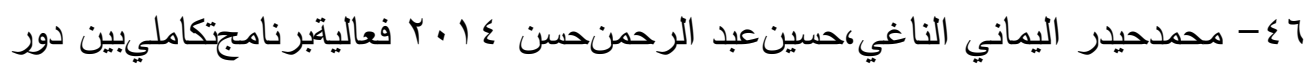

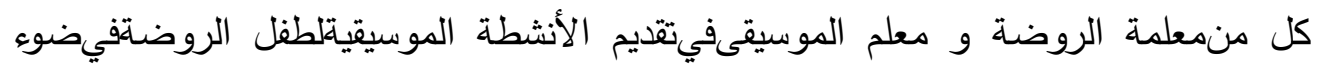

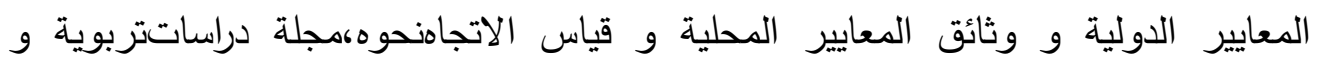

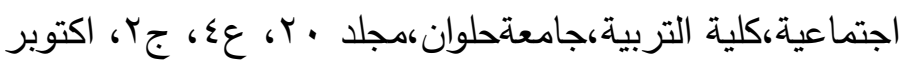

SV المتفوقين والعاديين، المؤتمر العلمي الإقليميللموهبة، السعودية،مؤسسة الملكعبد العزيز ورجالمللموهوبين.

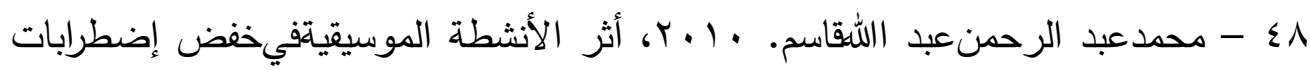

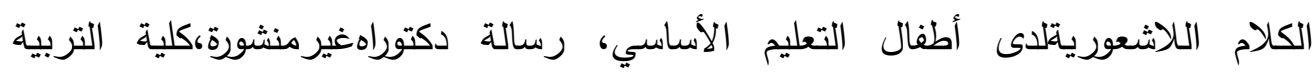
الموسيقية،جامعةحلوان.

؟ - - محمدحمودمحد أمينعارف. 1991، أثر الأنثطة الموسيقيةعلىتنمية القيم الإجتماعيةلطفل المرحلة الأولىمن التعليم الأساسي، رسالة دكتوراهيرمنشورة،كلية التربية التئية الموسيقية،جامعتحلوان.

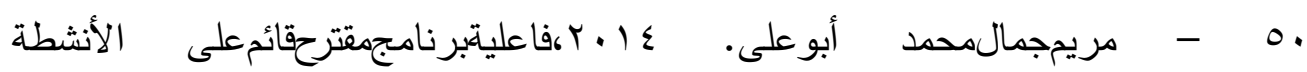
الموسيقيةلحدمنبعض اضطرابات النطقلدى طفلماقبل المدرسة، رسالةماجستير ،كلية رياض الأطفال،جامعة الإسكندرية.

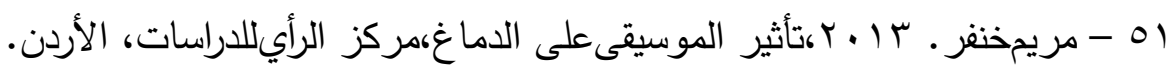

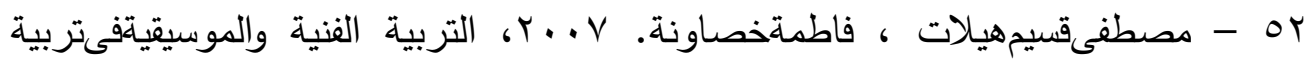
الطفل عمان، دار السيرةللنشر والتوزيع. 


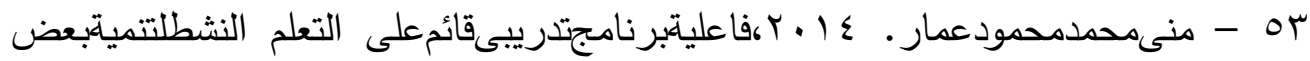

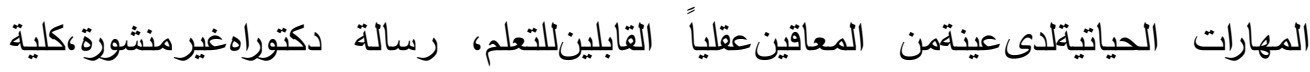
الاقتصاد المنزلى،جامعة المنوفية.

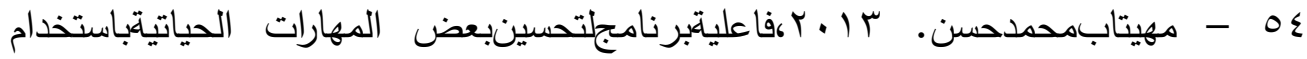

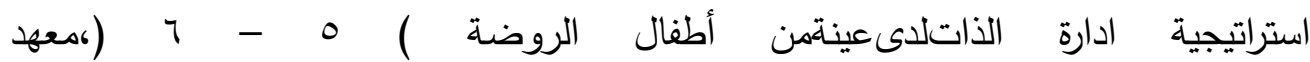
الطفولةللدراسات،جامعةعينشمس.

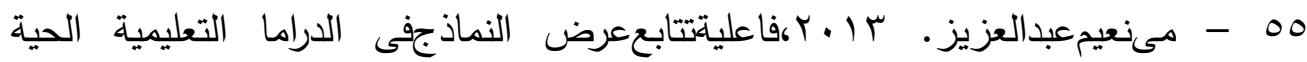
والمصورةلتنمية المهارات الحياتيةلىى التلاميذ الصم، رسالةماجستير غيرمنشورة،كلية

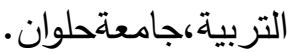

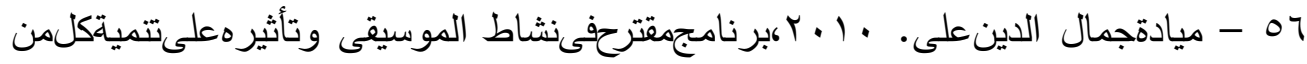
الذكاء والحس الموسيقىلدى الأطفالفىرحلةماقبل المدرسةفى الاسكندرية، رسالة دكتوراهغير منشورة،كلية رياض الأطفال،جامعة الاسكندرية. - نV

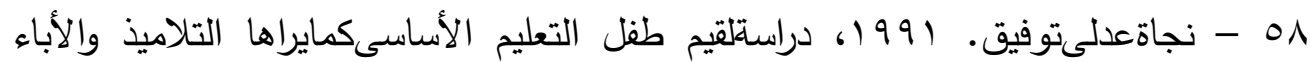

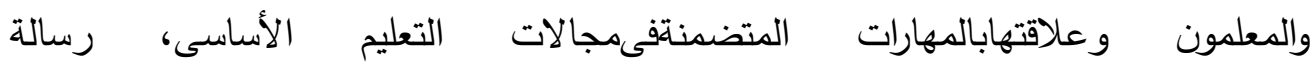
دكتوراةغيرمنشورة،كلية التربيةجامعة المنيا. 9ه - نجيبة الخضرى. . ... ب، الصحة النفسية،مركزنور الإيمان. • 7 - هالةجمالحماد ، نجوىنشأتمروَه. دليل المعلمة : المنهج المطورلرياض الأطفال " التعلم الذاتى "،توجياسلوك الأطفال،عمان، وزارة التربة والتعليم. آT - هبة اللهسعيد. r . . r،تقويممناهج الدراسات الاجتماعيةلصف الأول الأعدادىفىضوء المهارات الحياتية، رسالةماجستير غيرمنشورة،كلية التربية،جامعةعينشمس.

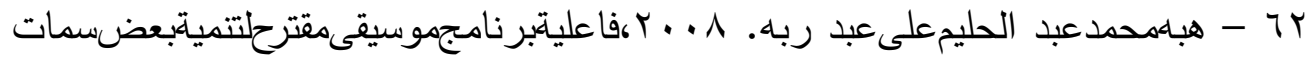
الشخصيةلدى رياض الأطفال، رسالة دكتوراهيرمنشورة،كلية رياض الأطفال،جامعة

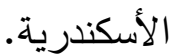




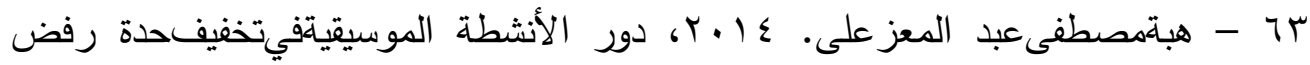
الطفلللمدرسة، رسالةماجستير ،كلية رياض الأطفال،جامعة الإسكندرية.

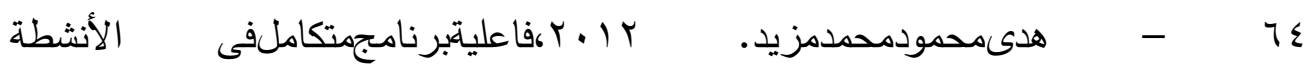

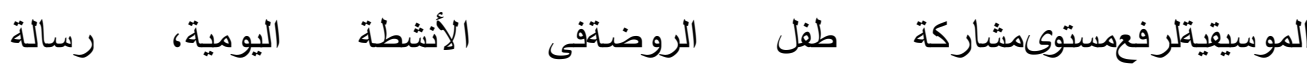
دكتوراهيرمنشورة،كلية رياض الأطفال،جامعة القاهرة.

10 - هشامحمد الصاوىمحد. 0. . . r، المشكلات السلوكيتفى النشاط الحركى لأطفالماقبل الدرسة وعلاقتهابيعضحاجاتهم الفنية، رسالة دكتوراهير منشورة،كلية التربية الرياضيةتلبنات،جامعة الأسكندرية.

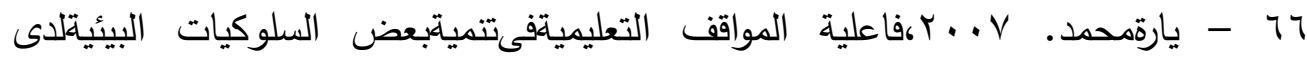
طفلماقبل المدرسة، رسالتماجستير غيرمنشورة،كلية التربية،جامعة أسيوط.

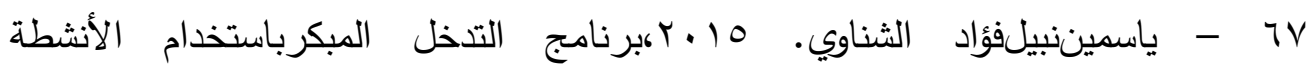

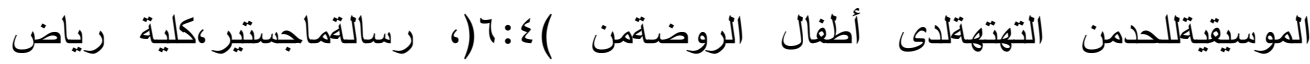
الأطفال،جامعة الإسكندرية.

\section{المراهج الخهنبية:}

1) Alvin J., Music Therapy, Jahn Baker, 1966.

2) Audrey J. Adair. Ready-To-Use: Music Activities Kit, Parker, 1994.

3) Barbara Staton and others. Music And You, Teacher's Edition Grade K, Macmillan New York, 1991.

4) Browning, R. and Stover, D. (2009) : Behavior modification in child treatment New York : Aldine Transaction.

5) Charles, C.m... Building Classroom Discipline, New York, Longman Publishing Co., 1992.

6) Degeroge Peal. Friendship and stories: using children literature teach friendship skills to children with learning disabilities ", 
1999, available on : http//www.idonline.org/id-index-teaching child-skills.html

7) 7. Dianne M. Gut. Bringing school into the 21 st century, Explorations of Education Do 10.1007/978-94-007-02680-4-3, Springer science Business Media B. V.2011.

8) Dowson .G (2005) : Life Skills Based Videodisc Curriculum social science record press vol 29.

9) Dreikurs R. and Cassel. Pupil Discipline without Tears, New York: Hawthorn, 19727.

10) Enhancing the Skills of Early Childhood Trainers - Guide to the Development of the Child, Bernard Van Leer Foundation/ UNESCO, 1995.

11) Essa, Era. A Practical Guide to Solving Pre-School Behavior Problems, Delman Publishers, Inc., 1990.

12) Gamble . Baxter (2006) : "Teaching Life Skills For Student Success".

13) Gordon, T. Teaching Children Self-Discpline - At Home and At School, New York: Times Books, 1989.

14) Graziano, A. (2008) : Behavior therapy with children, London : Aldine Transaction.

15) Hallie Kay Yopp, Ruth Helen Yopp. Songs and Activities for Phonemic Awareness, Harcourt Brace \& Company.

16) Kagan Paul and Routhedge, Response to Music, Brockle Hurst, B. London, 1971.

17) Kenneth Jameson and Pat Kidd, Pre-School Play, Studio Vista, 1974. 
18) Kimball Kathleen. Reducing negative behaviors of elementary school students through a program which honors values discussion, the Arts, and satisfies children basic needs, http//orders.edrs.com/members/sp.cfm? AN=ED 426816, 1998.

19) Lan Beck, Karen King. Oranges and Lemons, Singing and dancing games, Oxford University Press: New York, 1990.

20) Lois Choksy, David Brummitt. 120 Singing Games and Dances for Elementary Schools, Prentice-Hall, Inc.: New Jersey, 1987,

21) Michiko Yurko, Music Mind Games, A Warner Music Group company, 1992.

22) Nercel \& Metri Group. Engaude 21st Century Skills Literacy in the digital, 2003. age. http://www.ncrel.org/enguge.org/enguage

23) Page. Larry \& Bahamas. International Dictionary of education, London: Korean , 1971

24) Partnership for 21 st century Skills. Beyond the three Rs: voter attitudes toward 21st century Tucson, AZ:Author 2007.

25) Riehs, R. J: Daily Living Skills, The International Encyclopedia of Curriculum, Oxford. Pergramon Press, 1991.

26) Scott, Elizabeth, M.S. (2014). Music and Your Body : How Music Affects Us and Why Music Therapy Promotes Health, How and Why Is Music A Good Tool For Health?

27) Sleve , Rand Miyake A.. Individual differences in secong language proficiency : Does Musical ability Matter . Psychological scences , 17 (8) : 675-681 Music 2006.

28) Withehead, B.. The Effect of Music ability on students, DAI, 62 (08)-2710A Music 2001. 